\title{
LETTER
}

\section{A bedside definition of acute respiratory distress syndrome based on a conceptual model}

\author{
Shigeki Kushimoto* \\ See related commentary by Perel et al., http://ccforum.com/content/17/1/108, and related research by Kushimoto et al., \\ http://ccforum.com/content/16/6/R232
}

We would like to thank Perel for his discerning comments [1], published in the previous issue of Critical Care, about our study [2]. We agree with his pathophysiologybased view of the diagnosis of acute respiratory distress syndrome (ARDS).

In regard to his first concern, we excluded 14 patients, who were judged to have respiratory failure secondary to sepsis-induced increased pulmonary vascular permeability, because owing to hypovolemia their values of extravascular lung water indexed to predicted body weight (extravascular lung water index, or EVLWI) were less than $10 \mathrm{~mL} / \mathrm{kg}$. Because EVLWI in patients with ARDS correlated not only with pulmonary vascular permeability but also with cardiac preload [2], we interpreted that their low levels of EVLWI could be secondary to inappropriate preload. Although the mechanisms of hypoxemia were unclear, ventilation/perfusion mismatch may occur because of lung perfusion failure. The pathophysiology of the condition of these patients must be clarified in the future.

In regard to the concern that the experts may have had some idea of the pulmonary vascular permeability index (PVPI) value during the exclusion and allocation processes, the value of EVLWI was provided only to determine whether the patients had pulmonary edema (EVLWI of at least $10 \mathrm{~mL} / \mathrm{kg}$ ), and the value itself was not discussed during the review process. Therefore, estimating the PVPI value must be impractical.

We believe that the direct measurement of PVPI and EVLW will provide an important advance over current methods of assessing the presence and origin of lung edema and the precise condition of ARDS [3] and could be incorporated into the future definition of ARDS.

\section{Author's response}

Azriel Perel

I thank Kushimoto for addressing my commentary [1] on his group's study on the clinical usefulness of EVLWI and PVPI in defining ARDS [2]. Kushimoto points out that the reason for excluding 14 patients from the final analysis was that, although they were judged to have sepsis-induced increased pulmonary vascular permeability, they had normal EVLW values due to inappropriate preload (hypovolemia). Furthermore, he believes that the weak correlation between EVLWI and the indexed intrathoracic blood volume (ITBVI) supports this physiologic explanation.

Fluid loading indeed may increase EVLW [4] whereas the institution of negative fluid balance therapy may decrease elevated EVLW values [5]. However, in the

${ }^{*}$ Correspondence: kussie@emergency-medicine.med.tohoku.ac.jp

Division of Emergency Medicine, Tohoku University Graduate School of Medicine, 1-1 Seiryo-machi, Aoba-ku, Sendai 980-8574, Japan“" presence of sepsis-induced increased pulmonary vascular permeability, which is associated with severe hypoxemia (as, presumably, in the case of this excluded group of patients), pulmonary edema cannot be prevented or completely resolved by hypovolemia per se. The presence of such a theoretical extreme hypovolemia can also be ruled out in these patients because patients with a cardiac index of less than $1.5 \mathrm{~L} /$ minute per $\mathrm{m}^{2}$ were excluded from the study [2]. Furthermore, Figure 4 in the article by Kushimoto and colleagues [2] shows that ARDS patients with normal ITBVI values (850 to $1,000 \mathrm{~mL} / \mathrm{m}^{2}$ ) may have very high EVLWI values. Indeed, the combination of hypovolemia and pulmonary edema is not rare and may present a challenging 'therapeutic conflict' [6]. I agree with Kushimoto that the pathophysiology of these patients needs further clarification.

\section{Abbreviations}

ARDS, acute respiratory distress syndrome; EVLWI, indexed extravascular lung water; ITBVI, indexed intrathoracic blood volume; PVPI, pulmonary vascular permeability index. 


\section{Competing interests}

SK declares that he has no competing interests. AP is a member of the Medical Advisory Board of Pulsion Medical Systems, Munich, Germany.

\section{Acknowledgments}

SK thanks the members of the PiCCO Pulmonary Edema Study Group for their cooperation.

\section{Published: 14 March 2013}

\section{References}

1. Perel A: Extravascular lung water and the pulmonary vascular permeability index may improve the definition of ARDS. Crit Care 2013, 17:108.

2. Kushimoto S, Taira Y, Kitazawa Y, Okuchi K, Sakamoto T, Ishikura H, Endo T, Yamanouchi S, Tagami T, Yamaguchi J, Yoshikawa K, Sugita M, Kase Y, Kanemura T, Takahashi H, Kuroki Y, Izumino H, Rinka H, Seo R, Takatori M, Kaneko T, Nakamura T, Irahara T, Saito N, Watanabe A, Study Group PP: The clinical usefulness of extravascular lung water and pulmonary vascular permeability index to diagnose and characterize pulmonary edema: a prospective multicenter study on the quantitative differential diagnostic definition for acute lung injury/acute respiratory distress syndrome. Crit Care 2012, 16:R232.

3. ARDS Definition Task Force, Ranieri VM, Rubenfeld GD, Thompson BT, Ferguson ND, Caldwell E, Fan E, Camporota L, Slutsky AS: Acute respiratory distress syndrome: the Berlin Definition. JAMA 2012, 307:2526-2533.

4. Aman J, Groeneveld AB, van Nieuw Amerongen GP: Predictors of pulmonary edema formation during fluid loading in the critically ill with presumed hypovolemia. Crit Care Med 2012, 40:793-799.

5. Mitchell JP, Schuller D, Calandrino FS, Schuster DP: Improved outcome based on fluid management in critically ill patients requiring pulmonary artery catheterization. Am Rev Respir Dis 1992, 145:990-998.

6. Kirov MY: Pulmonary edema in hypovolemic patients: how can we predict it in clinical practice? Crit Care Med 2012, 40:994-995.

doi:10.1186/cc12539

Cite this article as: Kushimoto S: A bedside definition of acute respiratory distress syndrome based on a conceptual model. Critical Care 2013, 17:418. 